\title{
Strength and erosion mechanism of soft bedrock under high shear stresses
}

\author{
Li Zhijing ${ }^{1,2, a}$ and Jin Zhongwu ${ }^{1,2}$ \\ ${ }^{1}$ Changjiang River Scientific Research Institute, Wuhan 430010, China \\ ${ }^{2}$ Collaborative Innovation Center for Geo-Hazards and Eco-Environment in Three Gorges Area, Hubei Province, Yichang 443002, China
}

\begin{abstract}
Bedrock erosion plays a critical role in mountain river channel evolution, especially, where there are hydro-projects with high velocity flow conditions. In this study, laboratory experiments are carried out to investigate strength and erosion mechanism of soft bedrock under high shear stresses by high velocity open channel flows. Prototype bedrock from the upper reaches of Yangtze River is employed as testing samples. New observed dataset is generated concerning the flow, bedrock strength and evolution of bedrock erosion, which can be exploited to evaluate bedrock erosion rate and test mathematical bedrock erosion models.
\end{abstract}

\section{Introduction}

Bedrock erosion processes are believed to play important roles in the evolution of mountain river channels and their associated hydro-projects. During the last decade, there has been a rapid advancement in the development of models of mountain landscape evolution. These models have contributed to the understanding of the fundamental mechanisms underlying landscape evolution [1-6].

Generally, the main mechanisms responsible for bedrock erosion including hydraulic scour (plucking of rock fragments by fluid shear stress or differential fluid pressure) and abrasive scour (interaction between rock and moving sediment particles) [7]. It is possible that hydraulic scour may dominate on one reach, whereas abrasive scour may dominate on another. Alternatively, both mechanisms may operate concurrently to erode the bedrock on some rivers. A discussion of how to qualitatively identify the erosion mechanisms operating on a reach was presented by Whipple et al. (2000) [8]. A review was also provided by Lai and Greimann (2009) [9]. However, it is cautioned that the mechanisms are interrelated. Hydraulic scour can occur without the assistance of sediment particles but is influenced by sediments through particle-rock collision and sediment deposition. Similarly, abrasive scour is also strongly linked to hydraulic flow characteristics such as shear stress and turbulence.

In this study, only the hydraulic processes are considered, and particular attention is paid to the bedrock erosion in the upper reaches of the Yangtze River. Clear water alone can cause bedrock scour by instantaneous or progressive failure of closed-end rock joints or by dynamic ejection of single rock blocks [10]. Hydraulic scour may be an important mechanism for weak or highly fractured rock, as reviewed by Sklar and Dietrich (2004) [4]. Additional review was also provided by Tomkin et al.
(2003) and Sklar and Dietrich (2006) [11, 12]. In the upper reaches of Yangtze River, many alluvial rivers are characterized by the presence and exposure of soft bedrock that consists of mainly mudstone and sandstone with relatively lower compressive strengths. During flood season, the floods have become more and more frequent. These floods significantly erode the exposed soft bedrock and lead to damage to bridge pier foundations, diversion structures, and other infrastructure. Evaluation of bedrock erosion rate requires quantification of bedrock characteristics, together with hydraulic processes. Key geomorphic controls, such as rates of river incision or hillslope erosion, are often unknown, as valid data describing the relationships between rates of bedrock erosion and hydraulic processes are not sufficient.

Here we present 18 runs of experiments on soft bedrock erosion. A flume is purposely designed to generate high velocity open channel flow, and prototype bedrock including mud-rock and sand-rock from the upper reaches of Yangtze River are employed as testing samples. For each run, detailed measurements of the flow and bedrock erosion processes are conducted.

\section{Experimental Set-Up}

The experiments were conducted in a tilting bed flume at Changjiang River Scientific Research Institute (Figure 1). The tilting flume is made by Plexiglas, has a width of 0.4 $\mathrm{m}$, a length of $20 \mathrm{~m}$ long and a bed slope fixed at 0.035 . In order to relate experimental studies to field conditions, as we propose to do, the upstream of this flume is equipped with a high head water tank, by which high velocity open channel flows with a maximum value of $6.0 \mathrm{~m} / \mathrm{s}$ can be generated. In the test section of the flume, there is a notch designed to fix bedrock samples. Before each run, a bedrock sample is inserted into the notch, flush with the surface. The flat sample area exposed to

\footnotetext{
a Corresponding author: 1zjketty@126.com
} 
the flow is round with a diameter of $7.0 \mathrm{~cm}$. The magnitude of erosion was determined by weighing the erodible sample block before and after the experiment and obtaining the mass loss.

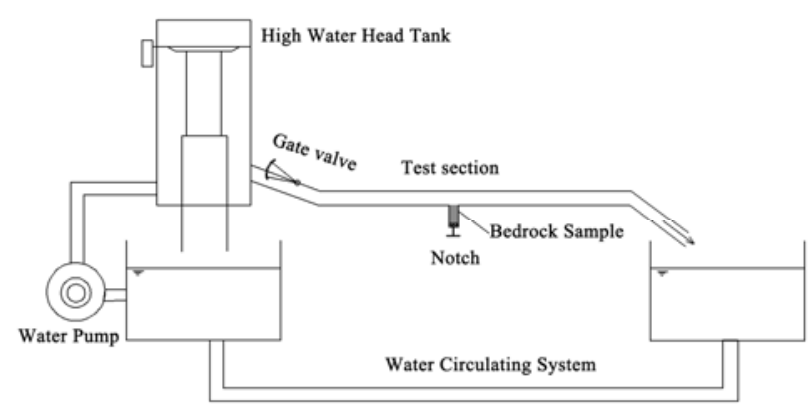

Figure 1. Illustration of the flume used to conduct bed erosion experiments.

\section{Field Survey}

The upper reaches of the Yangtze River cover a region from the Three Gorges Dam to the River's origin. The total area is about 1005 thousand $\mathrm{km}^{2}$ with a total population of 160 million, which accounts for $58.9 \%$ of the area and $35 \%$ of the population in the valley, respectively $[13,14]$. Within this area, $90 \%$ or more of the land is mountains and plateaus, in which the ecosystem is very fragile and subject to soil and bedrock erosion due to inappropriate use of land. On the other hand, the Yangtze River Basin is of great economic significance, with its economic productivity amounted to almost half of China's Gross National Product (GNP) during the 1990s. In addition, within the Yangtze River Basin, bedrock erosion problems associated with energy projects such as the Three Gorges Dam (TGD) and the South-to-North Water Diversion Project $[15,16]$.

Soft bedrock samples including mud-rock and sandrock were collected from the main river channel within the area of Chongqing Province. These relatively weaker sample bedrocks eroded more readily than other hard rocks, and also more susceptible to hydraulic erosion, thus shortening the experimental duration needed to produce measurable wear. Samples of bedrock are taken at possible foundation locations, boring method was used, and the erodible samples were cast into cylinder blocks with diameter of $7.0 \mathrm{~cm}$ and later cut into flume-ready samples. All samples were kept in a sealed box after sampling until laboratory analysis (Table 1).

Table 1. Physical and mechanical characteristics of bedrock samples

\begin{tabular}{|c|c|c|c|c|}
\hline Sample & $\begin{array}{c}\text { Density } \\
(\mathrm{kg} / \mathrm{m} 3)\end{array}$ & Porosity & $\begin{array}{c}\text { Tensile Strength } \\
(\mathrm{Mpa})\end{array}$ & Remarks \\
\hline M-A & 2670 & 7.53 & 0.85 & \multirow{2}{*}{$\begin{array}{c}\text { Mud- } \\
\text { rock }\end{array}$} \\
\hline M-B & 2678 & 7.34 & 1.09 & \\
\hline M-C & 2685 & 7.12 & 1.21 & \multirow{2}{*}{$\begin{array}{c}\text { Sand- } \\
\text { rock }\end{array}$} \\
\hline S-A & 2713 & 6.34 & 1.58 & 1.74 \\
S-B & 2720 & 6.02 & 1.96 & \\
\hline S-C & 2725 & 5.87 & \multicolumn{2}{|c}{} \\
\hline
\end{tabular}

\section{Results and Discussion}

We conducted 18 runs of erosion experiments in which we varied hydraulic condition and bedrock strength (Table 2). The procedure for each experiment was as follows: An erodible sample was weighed and placed in the flume, its top surface level with the flume bed, and the flume was filled with still water until sample was completely water-saturated (after 48 hour this work). During the run, we documented the depth, velocity and slope of the flow. The duration of the experiment was chosen to be long enough to obtain significant wear, but not so long that the erodible sample degraded significantly lower than the flume bed. At the end of each run, the sample was removed, examined for wear marks, and weighed on subsequent days until they equilibrated to their dry weight. Typically only one run was obtained from the same sample before it was replaced due to extensive wear, but when possible, we obtained multiple runs from the same sample to test repeatability.

Table 2. Experimental Runs, Measured Variables, and Results

\begin{tabular}{|c|c|c|c|c|c|c|}
\hline Run & Sample & $\begin{array}{c}\text { Mean flow } \\
\text { velocity }(\mathrm{m} / \mathrm{s})\end{array}$ & $\begin{array}{c}\text { Flow depth } \\
(\mathrm{cm})\end{array}$ & Water slope & $\begin{array}{c}\text { Eroded mass } \\
(\mathrm{g})\end{array}$ & $\begin{array}{c}\text { Duration } \\
(\mathrm{s})\end{array}$ \\
\hline 1 & M-A & 3.0 & $6.7 \pm 1.0$ & 0.035 & 27.60 & 7200 \\
\hline 2 & M-A & 3.5 & $14.0 \pm 1.5$ & 0.035 & 25.92 & 5200 \\
\hline 3 & M-A & 4.0 & $22.9 \pm 2.0$ & 0.035 & 25.52 & 3400 \\
\hline 4 & M-B & 3.0 & $6.7 \pm 1.0$ & 0.035 & 26.48 & 8000 \\
\hline 5 & M-B & 3.5 & $14.0 \pm 1.5$ & 0.035 & 27.36 & 6000 \\
\hline 6 & M-B & 4.0 & $22.9 \pm 2.0$ & 0.035 & 26.24 & 4200 \\
\hline 7 & M-C & 3.0 & $6.7 \pm 1.0$ & 0.035 & 26.88 & 8800 \\
\hline 8 & M-C & 3.5 & $14.0 \pm 1.5$ & 0.035 & 27.36 & 6800 \\
\hline 9 & M-C & 4.0 & $22.9 \pm 2.0$ & 0.035 & 27.04 & 5000 \\
\hline 10 & S-A & 3.0 & $6.7 \pm 1.0$ & 0.035 & 27.28 & 9200 \\
\hline 11 & S-A & 3.5 & $14.0 \pm 1.5$ & 0.035 & 26.16 & 7400 \\
\hline 12 & S-A & 4.0 & $22.9 \pm 2.0$ & 0.035 & 26.40 & 5600 \\
\hline 13 & S-B & 3.0 & $6.7 \pm 1.0$ & 0.035 & 28.16 & 10000 \\
\hline
\end{tabular}




\begin{tabular}{|l|c|c|c|c|c|c|}
\hline 14 & S-B & 3.5 & $14.0 \pm 1.5$ & 0.035 & 26.08 & 8200 \\
\hline 15 & S-B & 4.0 & $22.9 \pm 2.0$ & 0.035 & 26.24 & 6400 \\
\hline 16 & S-C & 3.0 & $6.7 \pm 1.0$ & 0.035 & 27.60 & 10800 \\
\hline 17 & S-C & 3.5 & $14.0 \pm 1.5$ & 0.035 & 26.72 & 9000 \\
\hline 18 & S-C & 4.0 & $22.9 \pm 2.0$ & 0.035 & 26.32 & 7200 \\
\hline
\end{tabular}

To analyze the erosion process with different conditions, we define the erosion rate as the ratio of the eroded mass and the erosion duration, and calculate the bed shear stress by $\tau=\rho g h J$, where $\rho$ is the density of water, $g$ is the gravity acceleration, $h$ is the flow depth, and $J$ is the water slope. Figure 2 shows the plot of erosion rate versus bed shear stress for different bedrock samples. It can be seen that erosion rate generally increases with the increase of shear stress for all samples, and the increasing trend decreases with the increase of tensile strength.

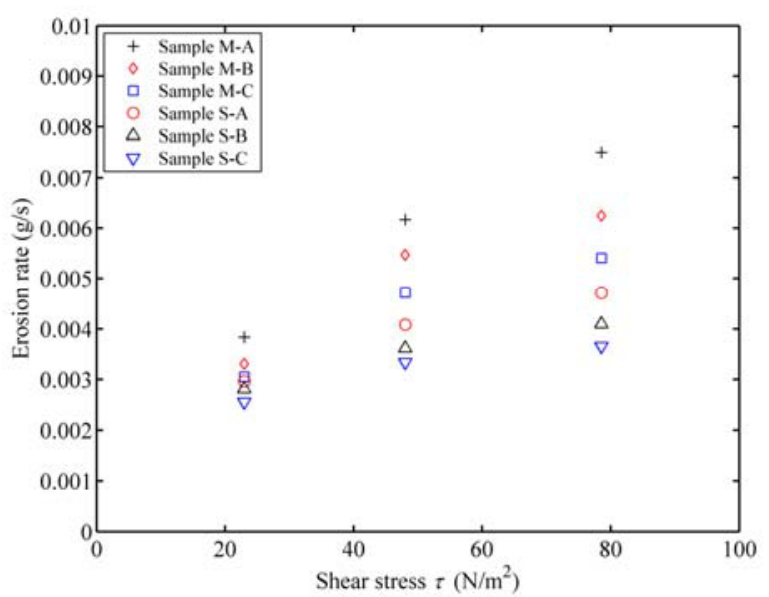

Figure 2. Plot of erosion rate versus bed shear stress for different bedrock samples.

Figure 3 presents the plot of erosion rate versus tensile strength for different bed shear stresses. It shows that if keep the shear stress constant, erosion rate decreases approximately with the square of the tensile strength. Hsu et al. (2008) conducted experimental study of bedrock erosion by granular flows, and explored the relationship between erosion of a synthetic bedrock sample and variables such as grain size, shear rate, water content, and bed strength [17]. It is interesting to see that their work also suggested that the bedrock erosion rate increases with the increase of shear rate and decreases with the increase of tensile strength. Particularly, our experiments employed prototype bedrock samples and high velocity open channel flow condition, which is closer to natural scale. It is acknowledged that to make the analysis of bedrock erosion more mechanistic, more field measurements are needed.

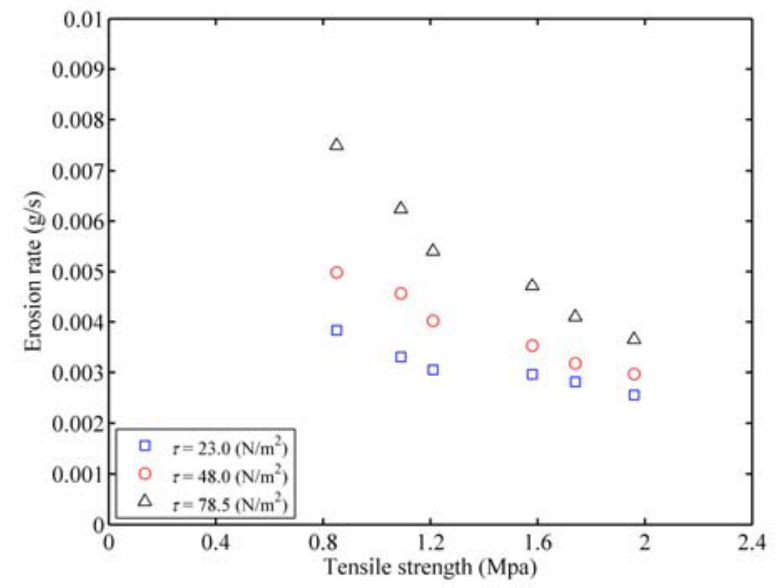

Figure 3. Plot of erosion rate versus tensile strength for different bed shear stresses.

\section{Summary}

Experiments on soft bedrock erosion have been conducted. A flume is purposely designed to generate high velocity open channel flow, and prototype bedrock including mud-rock and sand-rock from the upper reaches of Yangtze River are employed as testing samples. New observed dataset is generated concerning the flow, bedrock strength and evolution of bedrock erosion, which can be exploited to evaluate bedrock erosion rate and test mathematical bedrock erosion models.

\section{Acknowledgements}

The research is funded by Natural Science Foundation of China (Grants No. 51479009 and 51339001), and the special fund for basic scientific research business of central public research institutes (CKSF2016011/HL).

\section{References}

1. Howard, A. D. (1994). "A detachment-limited model of drainage basin evolution.” Water Resour. Res., 30, 2261-2285.

2. Tucker, G. E., and Slingerland, R. L. (1994). "Erosional dynamics, flexural isostasy, and longlived escarpments: A numerical modeling study." J. Geophys. Res., 99, 12,229-12,243.

3. Whipple, K. X., and Tucker, G. E. (2002). "Implications of sediment-flux dependent river incision models for landscape evolution." J. Geophys. Res., 107(B2), 2039, doi: 10.1029/2000JB000044. 
4. Sklar, L. S., and Dietrich, W. E. (2004). "A mechanistic model for river incision into bedrock by saltating bed load." Water Resour. Res., 40, W06301, doi: 10.1029/2003WR002496.

5. Gasparini, N. M., Bras, R. L., and Whipple, K. X. (2006). Numerical modeling of non-steady-state river profile evolution using a sedimentflux-dependent incision model, in Tectonics, Climate and Landscape Evolution, edited by S. Willett et al., GSA Special Paper 398, Penrose Conference Series, Geol. Soc. of Am., 127-141.

6. Lamb, M. P., Dietrich, W. E. and Sklar, L. S. (2008). "A model for fluvial bedrock incision by impacting suspended and bedload sediment." J. Geophys. Res., 113, F03025, doi: 10.1029/2007JF000915.

7. Lai, Y. G., Greimann, B. P., and Wu, K. (2010). "Soft bedrock erosion modeling with a twodimensional depth-averaged model." J. Hydraul. Eng., 137(8), 804-814.

8. Whipple, K. X., Hancock, G. S., and Anderson, R. S. (2000). "River incision into bedrock: Mechanics and relative efficacy of plucking, abrasion, and cavitation." Geol. Soc. Am. Bull., 112(3), 490-503.

9. Lai, Y. G., and Greimann, B. P. (2009). "Rock erosion modeling for rivers in Taiwan and progress report of bank erosion and turbidity current modeling." Technical Rep. SRH-2009-40, Bureau of Reclamation, U.S. Dept. of the Interior, Denver.

10. Bollaert, E. F. R., and Schleiss, A. J. (2005). "Physically based model for evaluation of rock scour due to high-velocity jet impact." J. Hydraul. Eng., 131(3), 153-165.

11. Sklar, L. S., and Dietrich,W. E. (2006). "The role of sediment in controlling steady-state bed channel slope: Implications of the saltation-abrasion incision model." Geomorphology, 82(1-2), 58-83.

12. Tomkin, J. H., Brandon, M. T., Pazzaglia, F. J., Barbour, J. R., and Willet, S. D. (2003). "Quantitative testing of bedrock incision models for the Clearwater River, NW Washington State." J. Geophys. Res., 108(B6), 1-19.

13. Li, C. H, Gu, S. Z. (1992). "A study on the characteristics of soil and water loss in the upper reaches of the Yangtze River and corresponding countermeasures." Bulletin of Soil and Water Conservation, 12, 1-6 (in Chinese with English abstract).

14. Wang, X. T. (1998). "The control of soil and water loss in the upper reaches of the Yangtze River and agricultural and rural sustainable development." Issues in Agricultural Economy, 12, 40-44 (in Chinese with English abstract).

15. Zhang, J., Zhang, Z.F., Liu, S.M.,Wu, Y., Xiong, H., Chen, H.T. (1999). "Human impacts on the large world rivers: Would the Changjiang (Yangtze River) be an illustration?" Global Biogeochemistry Cycles, 13, 1099-1105.

16. Chen, J.Y., Chen, X.Q., Chen, S.L. (2003). Impacts and countermeasures of the South-To-North Water Diversion Projects on the ecological environment of Changjiang Estuary. In: Chen, J.Y. (Ed.), Impacts and Countermeasures of the South-To-North Water
Diversion Projects on the Ecological Environment of Changjiang Estuary. Publication of ECNU, Shanghai, pp. 1-12.

17. Hsu, L., Dietrich, W. E., and Sklar, L. S. (2008). "Experimental study of bedrock erosion by granular flows.” J. Geophys. Res., Earth Surface (2003-2012), 113(F2). 